\title{
Erratum to: Importance of formalin fixing conditions for HER2 testing in gastric cancer: immunohistochemical staining and fluorescence in situ hybridization
}

\author{
Yoriko Yamashita-Kashima • Sei Shu $\cdot$ Keigo Yorozu • \\ Kaoru Hashizume · Yoichiro Moriya · Kaori Fujimoto-Ouchi • \\ Naoki Harada
}

Published online: 20 March 2014

(c) The Author(s) 2014. This article is published with open access at Springerlink.com

\section{Erratum to: Gastric Cancer}

DOI 10.1007/s10120-013-0329-8

The following errors unfortunately occurred in this article.

The titles of Table 2 and Table 3 should be as follows:

Table 2 Effect of fixation conditions on HER2 immunohistochemistry (IHC) score in human gastric cancer xenografted tumors

Table 3 Effect of fixation conditions on the detailed histological assessment of HER2 IHC staining in human gastric cancer xenografted tumors

In addition, there is an error in Table 5. Under the column heading "Fixatives", the first column subheading should read "10\% neutral buffered formalin (NBF)".

Open Access This article is distributed under the terms of the Creative Commons Attribution License which permits any use, distribution, and reproduction in any medium, provided the original author(s) and the source are credited.

The online version of the original article can be found under doi:10.1007/s10120-013-0329-8.

Y. Yamashita-Kashima $\cdot$ S. Shu $\cdot$ K. Yorozu •

Y. Moriya $(\bowtie) \cdot$ K. Fujimoto-Ouchi $\cdot$ N. Harada

Product Research Department, Chugai Pharmaceutical Co., Ltd,

200, Kajiwara, Kamakura, Kanagawa 247-8530, Japan

e-mail: moriyayui@chugai-pharm.co.jp

K. Hashizume

Medical Plan Management Department, Chugai Pharmaceutical

Co., Ltd., 2-1-1, Nihonbashi-Muromachi, Chuo-ku,

Tokyo 103-8324, Japan 